\title{
Risk Control of Virtual Enterprise Based on Distributed Decision-Making Model
}

\author{
Zhaoying Ouyang ${ }^{1,2}$ \\ ${ }^{1}$ School of Marxism, Shanghai University of Finance and Economics, Shanghai 200434, China \\ ${ }^{2}$ School of Marxism, Shanghai Lixin University of Accounting and Finance, Shanghai 201209, China
}

Correspondence should be addressed to Zhaoying Ouyang; 20119003@lixin.edu.cn

Received 4 February 2021; Revised 17 March 2021; Accepted 20 March 2021; Published 30 March 2021

Academic Editor: Wei Wang

Copyright (C) 2021 Zhaoying Ouyang. This is an open access article distributed under the Creative Commons Attribution License, which permits unrestricted use, distribution, and reproduction in any medium, provided the original work is properly cited.

Virtual enterprise is a dynamic alliance of businesses, in which multiple members undertake joint research, development, manufacturing, operation, etc. The complexity of the relationship between business members, coupled with many new technologies or methods applied in the alliance operation, leads to more uncertain factors and difficulties in the operation and risk management of the virtual enterprise. The distributed decision-making model is a fast and effective decision-making model, in which dispersed intellectual resources and information resources are dynamically integrated through virtual organization forms and operating mechanisms, and the dynamic reorganization, result evaluation, and synthesis of the decision-making system are realized by certain control rules. On the basis of summarizing and analyzing previous research works, this paper expounded the research status and significance of the risk control of virtual enterprise; elaborated the development background, current status, and future challenges of distributed decision-making model; introduced the related works of decision-making variable calculation and constraint determination; constructed a risk control model for virtual enterprise based on distributed decision-making model; analyzed the multiobjective model and interval programming model of risk control; established a risk control approach for virtual enterprise based on distributed decision-making model; performed the optimal allocation of risk control funds and the selective optimization of backup allies; and finally conducted a case analysis. The study results show that, in view of the diversity of relationships between alliance businesses and the complexity of the distribution of cooperative areas, the distributed decisionmaking model can more reasonably describe the relationship between alliance members and accurately control the risks of virtual enterprise from multiple angles, which can effectively manage the risks of virtual enterprise. The study results of this paper provide a reference for further research on the risk control of virtual enterprise based on distributed decision-making model.

\section{Introduction}

Virtual enterprise is a running mode for dynamic alliance of businesses that undertake joint research, development, manufacturing, and operation, which can successfully meet the needs of rising global competition, quickly respond to changes in market demand, and improve the ability of enterprises in business competition. A virtual enterprise is formed in response to market opportunities that have appeared or is about to appear, in which there is generally one initiator or leader and each business or enterprise in the alliance has its own advantages, assumes common risks, and shares common interests [1]. At the same time, the complexity of the relationship between business members, coupled with many new technologies or methods applied in the alliance operation, leads to more uncertain factors and difficulties in the operation and risk management of the virtual enterprise [2]. For example, in addition to the uncertainty of the business environment, the problems of conflict of goals of alliance member companies, cooperation trust, complicated cooperative relations, limited capabilities of member companies, corporate ethics, information asymmetry, opportunistic behavior, etc. all can make the formation, operation, dissolution, and reorganization of virtual enterprises face many new risk management problems that need to be studied and resolved [3]. Therefore, research on the risk control of virtual enterprise is of great importance in commercial value and business or their related fields, which is also the main topic of this study [4]. 
Distributed decision-making model is a model proposed to achieve rapid and accurate decision-making under the conditions of high-speed and dynamic changes in the enterprise's living environment. This model can dynamically integrate the dispersed intellectual resources and information resources through virtual organization forms and operating mechanisms, which can also realize the dynamic reorganization, result evaluation, and synthesis of the decision-making system by certain control rules, and ultimately complete the decision goal quickly and effectively [5]. The agents in distributed systems have special prior knowledge and different decision-making functions of expert systems in different fields, which can observe certain characteristics of the environment or observe different areas of the environment [6]. This study first distinguishes the source, inducement, stage, and process of the risk and brings market risks to the operation of the virtual enterprise, which analyzes and compares the implementation results with the expected goals to measure the effect of the overall plan and the implementation results [7]. The risk assessment method can finally provide decision-makers with detailed decisionmaking information; it can accurately reflect which risk assessment index has the greatest impact on the overall risk of the enterprise, thereby providing a basis for decisionmakers to minimize or avoid those risks [8].

On the basis of summarizing and analyzing previous research works, this paper expounded the research status and significance of the risk control of virtual enterprise; elaborated the development background, current status, and future challenges of distributed decision-making model; introduced the related works of decision-making variable calculation and constraint determination; constructed a risk control model for virtual enterprise based on distributed decision-making model; analyzed the multiobjective model and interval programming model of risk control; established a risk control approach for virtual enterprise based on distributed decision-making model; performed the optimal allocation of risk control funds and the selective optimization of backup allies; and finally conducted a case analysis. The study results of this paper provide a reference for further research on the risk control of virtual enterprise based on distributed decision-making model. The detailed sections are arranged as follows: Section 2 introduces the methods and principles of decision-making variable calculation and constraint determination; Section 3 constructs a risk control model for virtual enterprise based on distributed decision-making model; Section 4 establishes a risk control approach for virtual enterprise; Section 5 conducts a case analysis; Section 6 is the conclusion.

\section{Related Works}

2.1. Decision-Making Variable Calculation. Decision-making parties establish a two-way communication link through the network to realize information exchange and data transfer in the decision-making process. According to the different forms of communication data, the communication content can be divided into two types: proprietary format data and general format information [9]. The former refers to special formatted data transmitted and processed in agreed specifications or specified formats in accordance with the requirements of the subtask decision-making model. The format of these data is determined when the sub-decisionmaking model is established and must be supported by specific software and communication protocols [10]. The latter includes all general information in nonproprietary formats, such as the above information release, the transfer of commercial documents between the two parties, and the network talks, etc., which can be transferred through a variety of means and forms. Different from the integrated architecture, the software architecture of the decentralized construction model does not have a unified integrated modeling environment, nor does it need to generate a model interface file and a modeling language as an intermediate layer [11]. While the decision-making partner's modeling tool generates and releases a decision-making server for a specific customer, it also generates a corresponding client program and releases it to the decision-making party for practical use. Compared with the integrated structure, the function and structure of the decision-making server are basically the same, and the decision-making client program becomes the user interface of the decision-making party and basic functions such as result display and communication connection [12].

The upper-level alliance leader company allocates budget funds for each member of the virtual enterprise; the lower-level alliance member companies select the optimal combination of risk control measures under the allocated budget funds to reduce risks. In the two-tier decision-making process, this model mainly considers the symmetry of information between the leader and the members [13]. The upper-level search is a continuous problem, and a continuous particle swarm algorithm needs to be designed for it; the lower-level search is a discrete problem, and a discrete particle swarm algorithm is designed for it. In the upper search, the size of the search space is mainly determined by the number of members in the virtual enterprise; in the lower search, the size of the search space not only is related to the number of members, but also determines the number of risk factors each member faces and the number of corresponding measures [14]. When the number of members of the virtual enterprise, risk factors, and measures is large, the scale of the upper and lower search space of the problem will increase rapidly and the virtual enterprise model will have many advantages, but there will be also risks faced by traditional enterprises [15]. At the same time, the new model of cooperation between the leader enterprise and the alliance member enterprise also brings new risks, such as the ability risk of the alliance member enterprise and the relationship between the leader and the alliance member. Credit risk and communication risk between foreign companies, foreign exchange risk, and exchange rate risk will also arise when cooperating with foreign companies [16].

2.2. Constraint Determination. In the two-layer distributed decision-making model, the lower model is contained in the upper model, and the lower model and the upper model are discrete and continuous problems, respectively. The objective function is usually nondifferentiable and difficult to solve by 
traditional optimization methods; followers make decisions based on the leader's decision-making, and their decisionmaking is premised on not violating the leader's decisionmaking [17]. The execution of the decision-making is accompanied by the consumption of resources, so this premise can be transformed into the one that the resources consumed by the followers in the decision-making process shall not exceed the number of resources allocated to it by the leader. In the process of selecting cooperative enterprises, the leader company can use the problem reduction method to simplify complex problems [18]. The leader company decides to invest in the development of a certain product based on market analysis and forecasts, or the leader company starts to develop and manufacture a certain product after receiving an order [19]. The basic building blocks of the product are analyzed through its own designers or commissioned design companies, and the leading company determines which modules it can produce and which modules need to seek cooperative companies based on their design capabilities, manufacturing capabilities, and economic interests. In other words, decomposing the design and manufacture of a complex product and manufacture of multiple relatively simple parts is in line with the reduction principle of artificial intelligence [20].

Virtual enterprises cross the theory of enterprise boundaries, enabling a single enterprise to incorporate a large number of external resources belonging to other enterprises into the track of self-development [21]. The boundary becomes increasingly blurred and tends to fade; virtual enterprises are not limited by geographical space, quickly integrate resources scattered around the world through information networks and logistics networks, and are not restricted by their own hardware, and their boundaries can be infinitely expanded [22]. Moreover, virtual enterprises can virtualize some functions and retain only core functions, while other functions can break through the limitations of their own functions with the help of external forces. The membership and withdrawal of its members are completed through negotiation, and the organization is not substantive [23]. Each node constituting the network is equal. The identity maintains an interactive connection, its structure is an infinitely connected network structure, which will not be affected by factors such as the control range and monitoring mechanism, and its boundary does not exist. The members of the virtual enterprise have independent legal personality, but the enterprise alliance itself is not a real enterprise [24]. Although its function far exceeds the sum of the individual alliance members, it does not have compulsory alliances in terms of property rights. The right of contact between employees and enterprises and the virtual enterprise realizes the sharing of different dedicated assets under the premise of no transfer of property rights [25].

\section{Risk Control Model for Virtual Enterprise Based on Distributed Decision- Making Model}

3.1. Multiobjective Model for Risk Control. In distributed decision-making theory, according to the upper-level decision-makers' mastery of the lower-level preferences and the actual needs of the problem, the upper level can use different methods to predict the lower-level preference structure, thereby generating different prediction lowerlevel models. Based on the prediction of the lower-level model preference and the risk information of each stage, the upper-level model decides the reserve funds for risk control at each stage and transmits this value to the real lower-level model; the lower-level model reserves funds according to risk control, and each stage in the actual risk situation determines the optimal risk control strategy.

Suppose there are elements $x_{1}, x_{2}, \ldots, x_{n}$ in the risk control layer of the virtual enterprise and take the control layer elements $x_{i j}$ as criterion; then, a judgment matrix can be constructed and the ranking vector $X_{i j}$ can be obtained by the characteristic root method:

$$
X_{i j}=\left[\begin{array}{cccc}
x_{11} & x_{12} & \ldots & x_{1 n} \\
x_{21} & x_{22} & \ldots & x_{2 n} \\
\vdots & \vdots & \ldots & \vdots \\
x_{n 1} & x_{n 2} & \ldots & x_{n n}
\end{array}\right],
$$

where $x_{i j}$ is the closeness degree, which is the fuzzy set of the partner and the worst reference benchmark; if the judgment matrix is made using the scale of analytic hierarchy process, the attribute judgment matrix $Q_{i j}$ can be obtained by some simple transformation, such as the following formula:

$$
Q_{i j}=\left\{\sum_{i, j=1}^{n} \frac{x_{i j}}{x_{i j-1}+x_{i j+1}}, i \neq j, x_{i j}(0.5+b), i=j,\right.
$$

where $x_{i j-1}$ is the degree of preference of each evaluation index in the minds of decision-makers; $x_{i j+1}$ is the set of evaluation indexes selected by partners; and $b$ is the relative weight of each index.

According to the combination rules, all parameters can be synthesized to obtain the basic confidence assignment $W_{i j}$ :

$$
W_{i j}=\sum_{i=1}^{n} \sum_{j=1}^{n} \frac{w}{e-r}\left(\frac{x_{i j}}{q}\right)^{2},
$$

where $w$ is the discount calculator; $q$ is the discount factor, and the larger the value of $q$, the closer the calculator is to the empty confidence function; $e$ is the basic confidence assignment; and $r$ is the basic confidence assignment of the identification framework.

The upper-middle level is mainly used to determine the reserved funds for risk control in each operation stage, while the lower level is mainly used to determine the specific risk control strategy for each operation stage. At the beginning of the formation of the alliance, it is necessary to reserve sufficient risk control funds, meet the risk control requirements, and achieve the maximum investment and risk control for risk management according to the estimated risk information at different stages of the operation of the alliance enterprise. At the beginning of each stage in the actual operation process, the specific risk control measures for this stage are determined according to the reserved funds and risk information data of this stage, and 
the reserved funds are fully utilized to optimize the risk control effect. Figure 1 shows the analytical framework of risk control for virtual enterprise based on distributed decision-making model.

Risk assessment is to evaluate and measure the existence of risks and the scope and extent of potential losses of risks. Its purpose is to analyze and identify those potential threats and risks with serious consequences and treat them as the key to preventing and dealing with their impact in order to formulate and select appropriate risk management methods and management. The endogenous system refers to the sum of the risk prevention institutions, mechanisms, countermeasures, methods, measures, etc. established within the virtual enterprise; the exogenous system refers to the relevant laws and regulations, credit, and media that play a preventive role in the virtual enterprise risk in the whole system. The selfcontrol of the endogenous system and the heteronomy of the exogenous system complement each other, and together they play a preventive and restrictive role in preventing and restricting virtual enterprise risks. The supervision of alliance member companies' performance of alliance contracts, cooperation agreements, etc. and the establishment of alliance risk management mechanisms and risk prevention systems, as well as alliance operation information feedback, inspection, transitive risk control, and exception handling, require alliance risk management agencies. The size of the organization can be determined according to the production scale of the opportunity product, the complexity of the technology and production and operation process, the difficulty of marketing, the number of alliance member companies, and the comparison of risk management costs and benefits.

3.2. Interval Planning Model for Risk Control. The initial population uses the method of random generation to generate the initial population. First, through the control of random numbers, it is ensured that each code in the chromosome meets the requirements of the number of funds for each measure; second, if the chromosome does not meet the remaining constraints, the chromosome is discarded. When the upper-level model is solved, the amount of data is very large due to the need to consider the risk control conditions of all stages globally; the lower-level model mainly determines the specific measures and capital investment to control each risk under the constraint of reserved funds. Qualitative methods can be regarded as comparisons of results and possibilities; for example, high risk is relative to medium or low risk, and qualitative methods rely on the analyst's experience and engineering judgment, so they tend to be subjective. The results of quantitative analysis are compared with company guidelines or decision-making to determine whether the risk is acceptable, and the total expected currency value of all risk events is the expected currency value of the plan. In order to use the expected currency value method, the risk must first be quantified, and the probability of the occurrence of a risk event and the consequences of the risk event must be determined. The currency value is usually used to express the consequences of the risk event and multiply the probability of occurrence of a risk event and the consequences of a risk event to obtain the expected currency value of each risk event. The framework of interval planning model for risk control based on distributed decisionmaking is shown in Figure 2.

From the perspective of the alliance as a whole, market risks, social environmental risks, and natural environmental risks are system external risks, in which technical risks and cooperation risks are system internal risks, and these five types of risks are interrelated. The fiercer the market competition, the higher the technical requirements of the company's products, which means the greater the company's technical risk; the more advanced the technology, the greater the company's advantage in market competition, and the smaller the market risk. In addition, in order to develop advanced technologies, enterprises should have a higher level of management, and scientific management will reduce the risk of developing advanced technologies; for example, the technical risks undertaken by enterprises are affected by market risks.

Relevant chance planning is an optimization theory that optimizes the chance function of time in an uncertain environment; for uncertain environment of the leader, it can be expressed as a random constraint $E\left(x_{i j}\right)$ :

$$
E\left(x_{i j}\right)=x_{i j}^{t}-x_{i j}^{u},
$$

where $t$ is the decision-making vector and $u$ is the random vector. For indicators that cannot be given quantitatively, the similarity coefficients related to it can only be assessed subjectively. Therefore, the leader's decision-making model can be expressed as

$$
R\left(x_{i j}\right)=\sqrt{p\left(\frac{o_{i j}-a_{i j}}{x_{i j}}\right)^{2}},
$$

where $R\left(x_{i j}\right)$ is the probability measure; $o_{i j}$ is the objective function; $q_{i j}$ is the deterministic decision-making benefit function of the leader's decision-making process; and $p$ is the possible decision-making benefit function of the random event.

Because the fuzzy comprehensive evaluation method simplifies the various internally complex and interrelated system risk evaluation indicators, it partially causes the loss of risk evaluation information. In the risk evaluation model, the risk evaluation information is successfully used, and the comparison method is integrated into the former super matrix and finally expressed in the form of comprehensive weight. The risk assessment method can finally provide decision-makers with detailed decision-making information. For example, it can accurately reflect which risk assessment index has the greatest impact on the overall risk of the enterprise, thereby providing a basis for decision-makers to minimize or avoid the risk. 


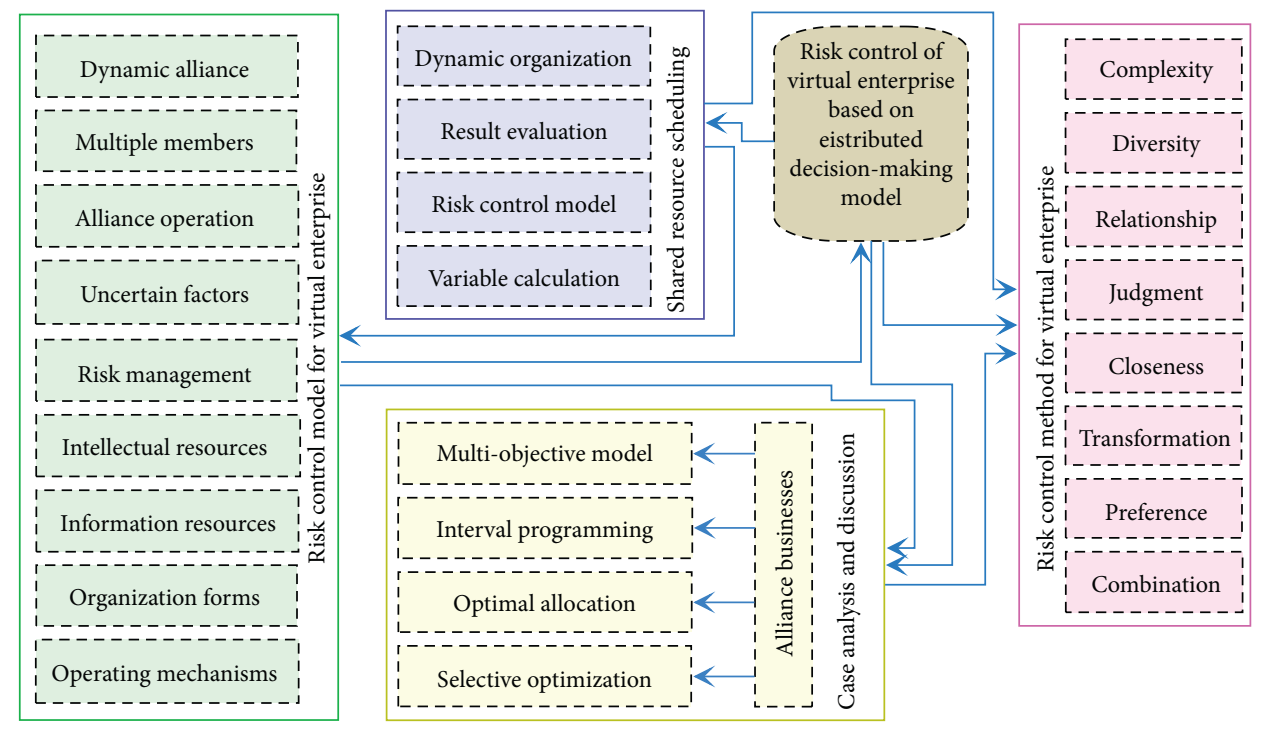

FIGURE 1: Analytical framework of risk control for virtual enterprise based on distributed decision-making model.

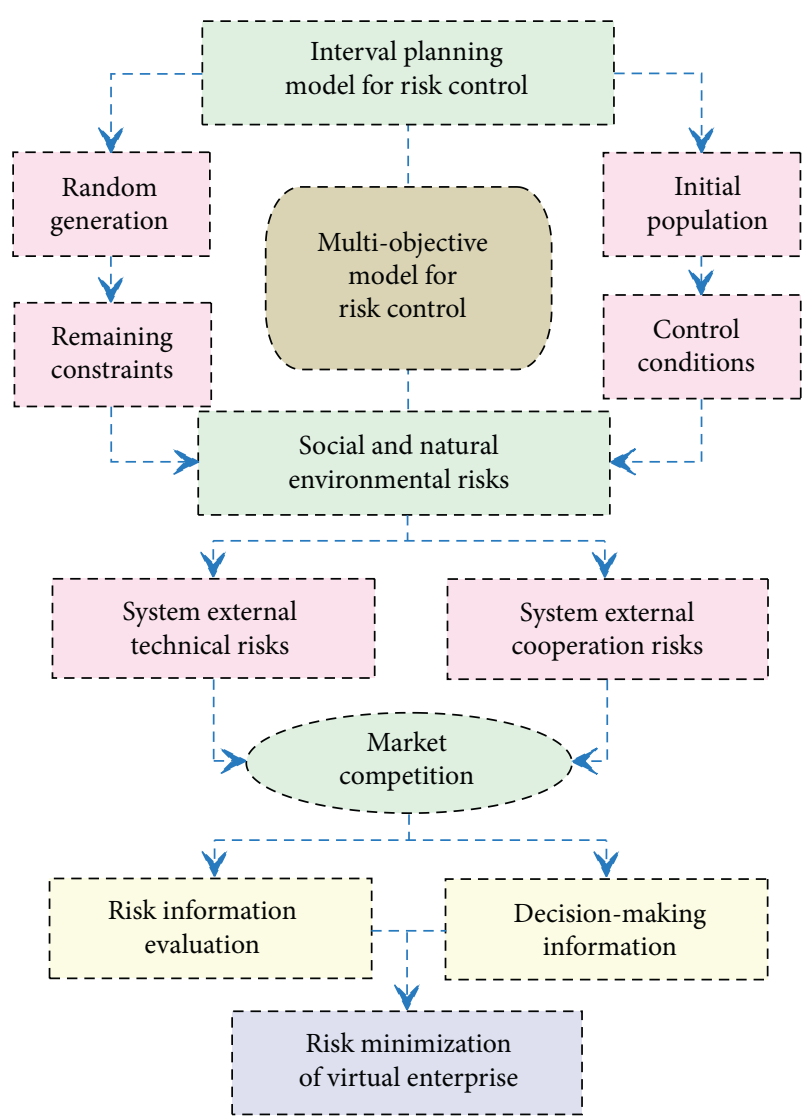

FIGURE 2: Framework of interval planning model for risk control based on distributed decision-making.

\section{Risk Control Method for Virtual Enterprise Based on Distributed Decision- Making Model}

4.1. Optimal Allocation of Risk Control Funds. The life cycle of a virtual enterprise includes the establishment phase, the operation phase, and the dissolution and the reorganization phase. In the whole process of the virtual enterprise life cycle, the influence of some risk factors is phased, the influence of some risk factors is a full process, and the influence of some risk factors is transitive. On the one hand, it comes from insufficient estimation of technical complexity in advance, and technical issues that are difficult to solve and market opportunities are the reasons for the existence of virtual enterprises. On the other hand, it comes from the insufficient degree of tacit understanding of technical cohesion and cooperation caused by differences in process conditions and technical strengths between different members. The first is the flexibility of the start-up time, which requires that the tasks that need to be processed from other members can be responded to in a short time; the second is the time of the process; that is, the cooperation between members should be coordinated in time ensuring that the corresponding tasks are completed within the time specified in the contract. The market identification errors of the leader companies and the blind identification of member companies will undoubtedly make the virtual enterprises at risk. The main reasons for the risks of market opportunity identification are based on product identification errors, confused by demand illusions. Based on the product demand quantity and quality requirements, the forecast deviation is large; since the product demand maintenance time is too short, it is quickly replaced by other products. The method and principle for optimal allocation of risk control funds are shown in Figure 3.

In the environment of virtual enterprise, the alliance needs to simulate the whole process of the overall economic operation of the enterprise and make decisions on finance, production, and sales. At the same time, under the premise of determining the sales volume and production tasks, the overall resources of the enterprise, including production equipment, manpower, and material resources, are optimized and planned. These decision-making problems are of different types, including 


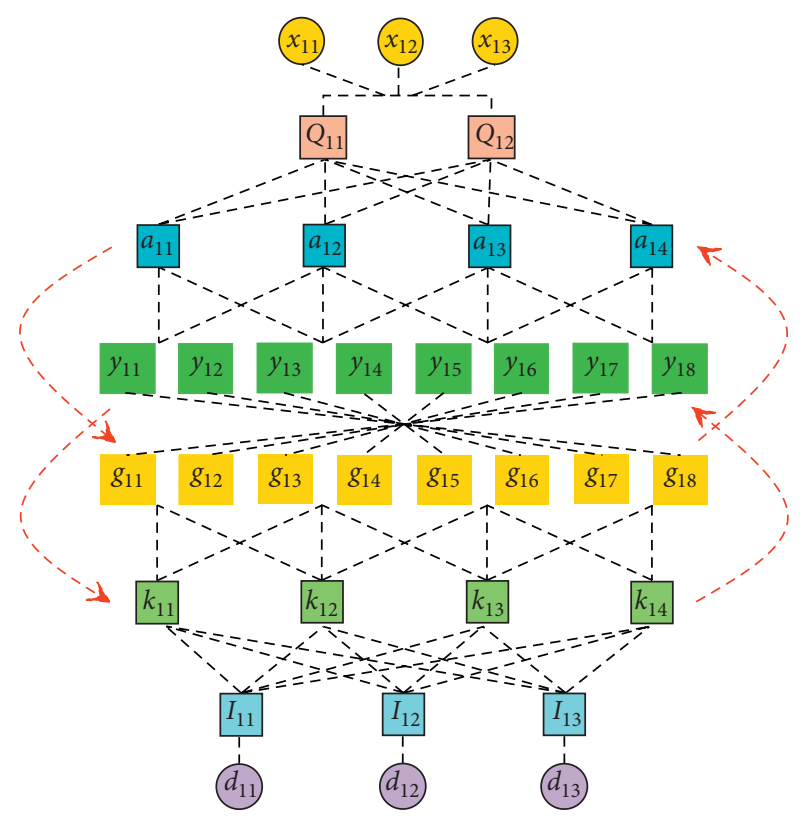

Figure 3: Method and principle for optimal allocation of risk control funds.

structured decision-making problems, semistructured decisionmaking problems, and unstructured decision-making problems, which bring great difficulties to the organizational decision-making of virtual enterprises.

If there are $y_{1}, y_{2}, \ldots, y_{n}$, a total of $n$ plans compose the plan set $Y_{n}=\left\{y_{1}, y_{2}, \ldots, y_{n}\right\}$, and the evaluation index of each plan constitutes the index set $Y_{m}=\left\{y_{1}, y_{2}, \ldots, y_{m}\right\}$. The evaluation value of $y_{i}$ for the $j$-th index is $y_{i j}$, and then the initial evaluation matrix $T_{i j}$ is established as

$$
T_{i j}=\left[\begin{array}{cccc}
y_{11} & y_{12} & \ldots & y_{1 n} \\
y_{21} & y_{22} & \ldots & y_{2 n} \\
\vdots & \vdots & \ldots & \vdots \\
y_{n 1} & y_{n 2} & \ldots & y_{n n}
\end{array}\right] .
$$

It selects the optimal value of each indicator in the candidate partners as the benchmark to normalize the indicators and divides the evaluation objects into two categories: the larger the optimal value, the better the income indicator; the smaller the optimal value, the better the cost indicator. The effective value calculation of multiple enterprises can give the evaluation target set $U_{i j}$ in the form of the following matrix:

$$
U_{i j}=s_{i j} x_{i j}+d_{i j}\left(x_{i j}-1\right)+g_{i j}\left(x_{i j}-2\right),
$$

where $s_{i j}$ is the effective score value of the $j$-th type index of the $i$-th company; $d_{i j}$ is the score value matrix of the $j$-th type index of the $i$-th company; and $g_{i j}$ is the score of the $j$-th evaluation target of the $i$-th company.

The agent extracts the feature vector from the environmental information as input and then obtains the single confidence function of each premise in the identification framework from the measurement function. Finally, the basic confidence assignment of agent is synthesized and output by the formula; the attribute judgment matrix is $I_{i j}$ :

$$
I_{i j}=\frac{x_{i j}}{h-1}\left(\frac{z \cdot l_{i j}}{c \cdot k_{i j}}\right),
$$

where $h$ is the input attribute set; $k_{i j}$ is the output attribute set; $l_{i j}$ is the price function; $z$ is the reliability of the output value; and $c$ is the output value cost.

The functional structure framework of the virtual enterprise decision-making support system reflects the integration of multiple decision-making support technologies and parallel use to deal with the diversity of decision-making problems in the virtual enterprise and also reflects the continuous emergence of data and knowledge processing technologies. Driven by the development process of the decision-making support system, its data knowledge processing capabilities have been enhanced, and its adaptability has expanded. In a virtual enterprise organization, the decision-making of organizational goals requires interactive coordination with many members in the organization; therefore, under the leadership of core members, how to build a decision-making support system for goal coordination and conflict resolution between members is an important issue in the future.

4.2. Selective Optimization of Backup Allies. The members of the alliance work around a certain link of the opportunity product and need to exchange related logistics and information flows between different legal entities. Since the alliance does not have administrative constraints on the member companies and the management methods and technical conditions of each member company, the difference in culture directly affects the exchange, flow, and coordination of related information. The management contract has stipulated the benefit distribution and loss sharing of the alliance members, but the inconsistency between the contract and reality makes it necessary to redistribute the benefits and losses of the opportunity products according to the specific contributions of the alliance members during the disintegration stage of the alliance, especially the distribution of intangible assets. Enterprises in the alliance cluster do not necessarily have to participate in the operation of every organization with alliance networks. Figure 4 shows the relationship between optimization indexes and weight coefficients of backup allies. Whether they participate or not depends entirely on whether they have the resources and capabilities to complete specific opportunities and goals; when a core company finds a new market opportunity, it can reform a new virtual enterprise. The risk management of virtual enterprise must first distinguish the source, inducement, stage, and process of the risk, which is the prerequisite of risk management. To fully identify the risk factors of virtual enterprises, scientific risk identification technology is needed and the member of each cooperation company can be the same as the last time or different.

Candidate partner companies propose evaluation goals and weighting coefficients according to the leader's evaluation goals, and after information processing by the alliance 


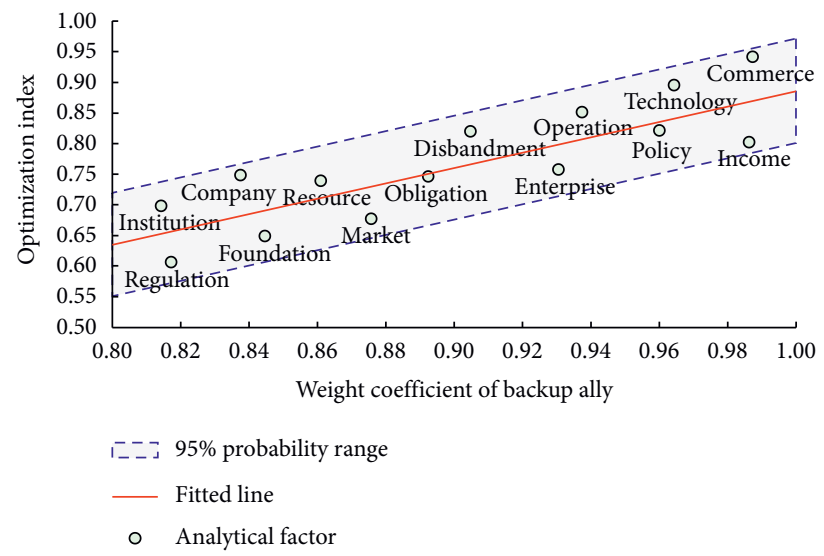

FIGURE 4: Relationship between optimization indexes and weight coefficients of backup allies.

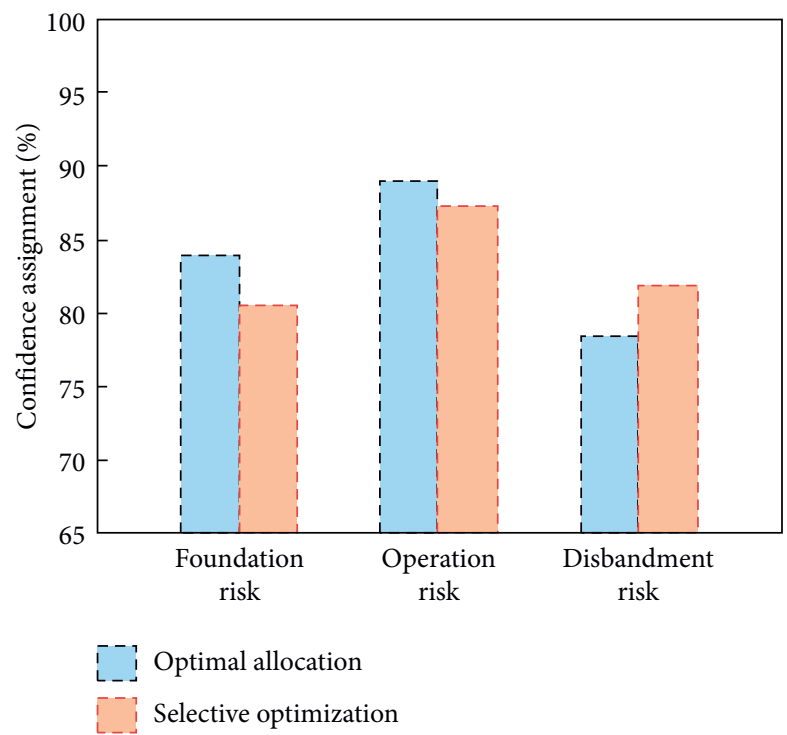

(a)

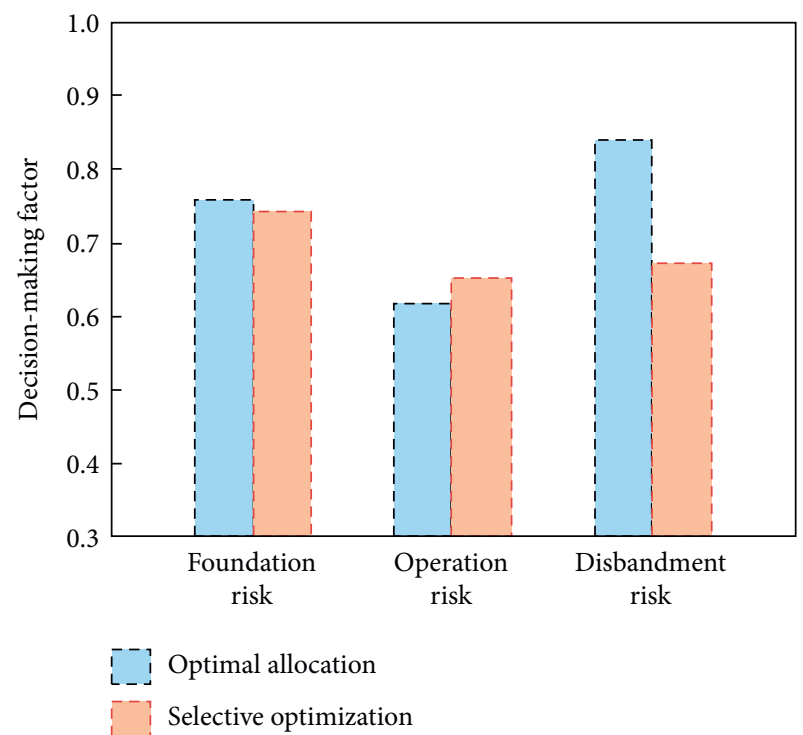

(b)

Figure 5: Confidence assignment (a) and decision-making factor (b) of the foundation, operation, and disbandment risk of virtual enterprise under optimal allocation and selective optimization.

center, the effective scores of candidate partner companies can be accurately obtained. If an enterprise is well managed and operated, then the enterprise that is allied with it can be expected to benefit from the alliance; otherwise, it will take a greater risk. The confidence assignment and decisionmaking factor of the foundation, operation, and disbandment risk of virtual enterprise under optimal allocation and selective optimization is shown in Figure 5. If consumer demand changes, then the opportunity for virtual enterprises will disappear, and there is no need to form virtual enterprises, but the initial investment in virtual enterprises will not be recovered; that is, changes in consumer demand will bring huge losses to virtual enterprises. If there are many competitors in the product market jointly developed by the virtual enterprise, it will be more difficult for the virtual enterprise to research and develop products in the future to occupy the market, which will bring market risks to the operation of the virtual enterprise; changes in the upstream market will also cause market risks. The important reason is that if raw materials in the upstream market are in short supply, the manufacturing cost of the virtual enterprise will increase, thereby increasing the price of the product. The increase in product price will bring certain difficulties for the virtual enterprise to occupy the market; the economic downturn will lead to a reduction in the disposable income of residents and reduce the total demand in the market.

The partners exchange plan information under the conditions determined by the collaboration process, so that the partners can obtain an overall understanding of the plan situation and identify whether the expected goals can be achieved. This process requires a common planning framework in which key performance indicators are used to measure common goals and conditions, and the planning results of individual domains and collaborative plans are compared. Based on the joint determination of values by all parties, two treatment methods are usually adopted for the 
situation that the planned deviation exceeds the scope. For the deviation caused by the individual characteristics of the partners, the plan between the partners is adjusted through the negotiation process to achieve the expected goals; the deviation caused by the changes in the structure and the external environment is an exception, and the cooperation mode and the goal of the collaborative plan will be realized. After the plan is implemented, it is necessary to analyze and compare the implementation results with the expected goals to measure the effect of the overall plan, and the implementation results that benefit all supply chain members are more easily accepted by all parties. However, when the implementation results of the collaborative plan cause some members to suffer losses, reasonable compensation methods need to be given, and the corresponding losses can be compensated by adjusting the profit distribution, so that the benefits of supply chain members are relatively balanced. At the same time, in the case that the implementation effect does not reach the expected goal, it is necessary to adjust and improve the plan.

\section{Case Analysis}

5.1. Experimental Design. The algorithm proposed in this paper uses computer language to program and calculate a large amount of simulation data. The results show that the above-mentioned solving idea can effectively obtain the optimal solution of the problem, and an example is analyzed below. A virtual enterprise of an enterprise needs to control risks in five stages: opportunity identification, partner selection, enterprise restructuring, alliance operation, and dissolution and liquidation. The total risk control fund is 200,000; the reasonable parameters determined by the simulation analysis are the population size of 500, the number of iterations of 800 , the crossover rate of 0.6 , and the mutation rate of 0.3 . In order to describe the risk status, the risk is divided into 9 levels from small to large, and it is assumed that the initial state of each risk factor and the impact on risk factors are known.

Fuzzy recognition is one of the basic methods of fuzzy system analysis. It is a method that considers the influence of multiple factors in a fuzzy environment to make a comprehensive decision-making on a certain matter for a certain purpose:

$$
P_{i}=\int_{i=1}^{m} \frac{z_{i}-c_{i}}{v_{i}}
$$

where $P_{i}$ is the mutual relationship between two enterprises; $z_{i}$ is the relationship and contract reached by the alliance as a whole; $c_{i}$ is the overall effect of the alliance; $v_{i}$ is the individual effect of a single enterprise; and $m$ is the cooperation period of the alliance.

In the fuzzy language information integration process for evaluating candidate partner indicators, the integration result often does not match the elements in the fuzzy language evaluation scale $A_{i j}$ :

$$
A_{i j}=\left(\alpha_{i j}-\beta_{i j}\right) \cdot \rho \cdot\left(\gamma_{i j}-\delta_{i j}\right)^{2},
$$

where $\rho$ is the balance factor; $\alpha_{i j}$ is the index value for selecting partners; $\beta_{i j}$ and $\gamma_{i j}$ are the impact of the two enterprises' respective efforts in failed knowledge innovation on the overall profit; $\delta_{i j}$ is the ability of the enterprise to convert the failed knowledge into profit.

After the risk measures are dealt with, the fuzzy description of the risk level of each risk factor changes accordingly. There are several treatment measures for each type of risk, and each measure handles risk factors to a different degree. Therefore, the vague description of the same risk handled by different measures is also different, and the purpose of risk planning is to optimize the combination of these measures to make the overall risk level the lowest under the circumstance that the cost of controlling risks is certain.

5.2. Result Analysis. In a distributed computing environment supported by computer networks, virtual enterprise companies can efficiently combine conventional organizations that are dispersed in time and space but with complementary capabilities and resources to improve their ability to solve problems and enhance their ability to respond quickly to challenging opportunities. Without changing their original working environment, widespread attention has been attracted, especially in the manufacturing industry. Virtual enterprises and crossfunctional project working groups have become the core concepts of the new generation of manufacturing. A virtual enterprise is a cross-enterprise dynamic organization formed under the constantly changing conditions of the global market environment, which is a brand new form of enterprise organization formed temporarily by multiple independent enterprises for a certain goal. The activity is the specific operation of the task, and the progress of the activity causes the change of the task state; at the same time, it must rely on certain resources and be controlled by the corresponding rules. Figure 6 shows the risk control efficiency and accuracy of different risk types of virtual enterprise. The business process in a virtual enterprise can be decomposed into a number of different specific projects according to the nature of the business process and the requirements of project management technology. These projects can be redecomposed at different levels and task granularity according to the needs of the virtual enterprise operation and management; therefore, a multiproject and multitask hierarchical management model is formed in a virtual enterprise.

Risk identification is the basis of the entire virtual enterprise's risk management work, and risk cannot be measured and managed without identification and verbal expression. The risk identification of virtual enterprise means that the risk team of the virtual enterprise develops systematic understanding and analysis through a large number of reliable information materials, recognizes various risk factors in the virtual enterprise, and then determines the risks faced by the virtual enterprise. Risk measurement is to measure the probability of occurrence of risk accident and the degree of loss for a certain specific risk of virtual enterprise. Risk measurement is carried out on the basis of risk identification. One of the existing approaches requires a common planning framework in which key performance indicators are used to measure common goals and 


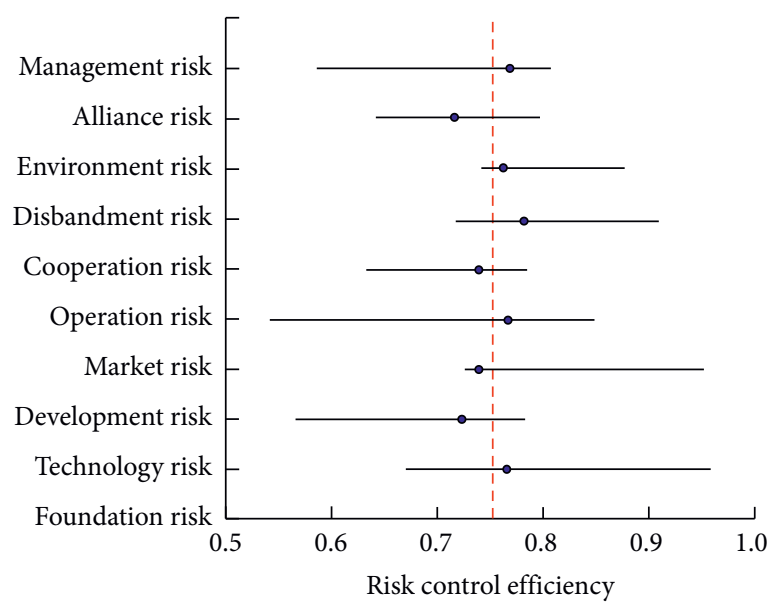

(a)

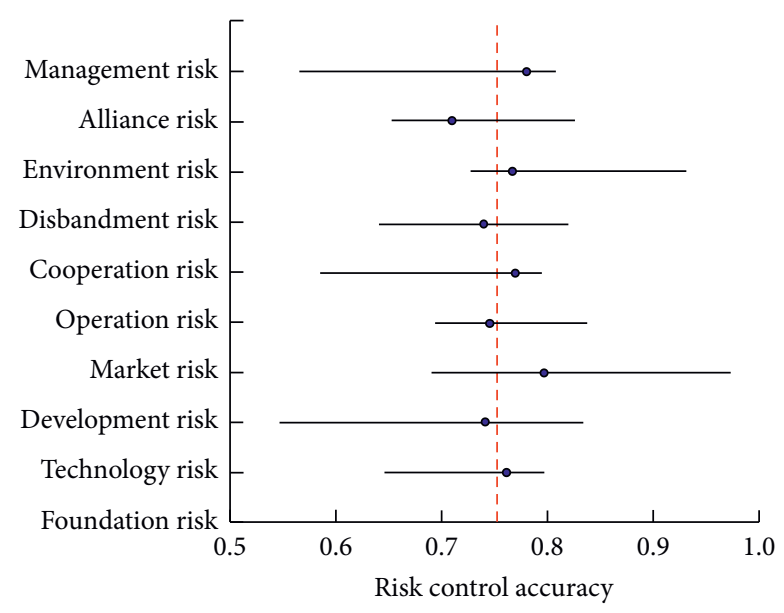

(b)

Figure 6: Risk control efficiency (a) and accuracy (b) of different risk types of virtual enterprise.

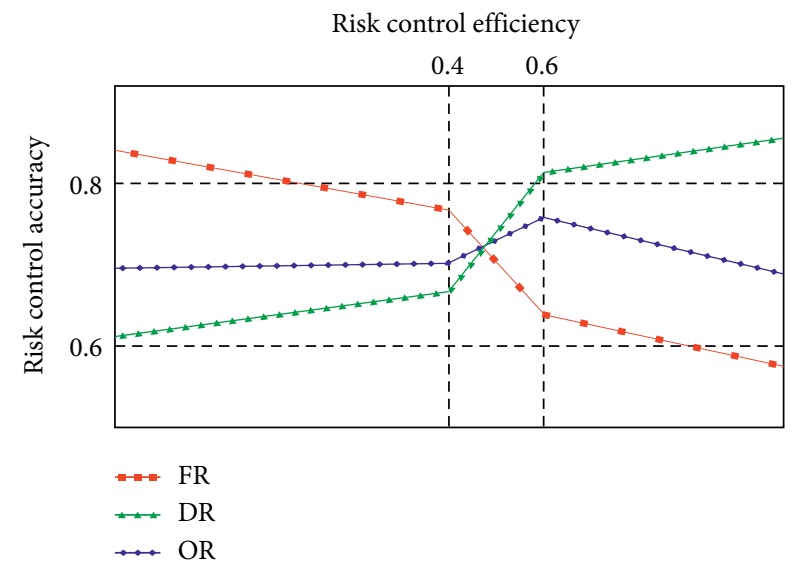

(a)

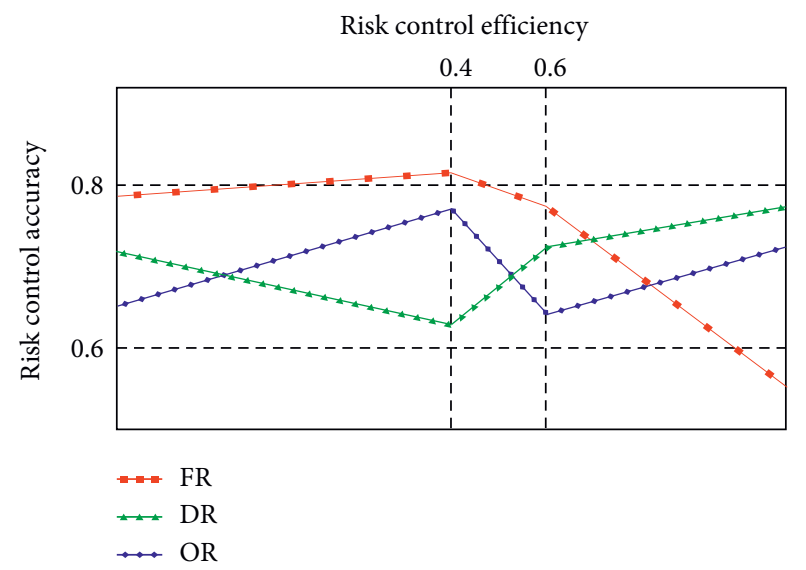

(b)

FIGURE 7: Relationship between risk control accuracy and efficiency of the foundation risk (FR), operation risk (DR), and disbandment risk (DR) of virtual enterprise under optimal allocation (a) and selective optimization (b).

conditions, and the planning results of individual domains and collaborative plans are compared. However, the approach in this study has stipulated the benefit distribution and loss sharing of the alliance members, but the inconsistency between the contract and reality makes it necessary to redistribute the benefits and losses of the opportunity products. Deviations in risk assessment may make the virtual enterprise face the risk of losing profit opportunities and bear the cost of conservative or aggressive strategy. In addition, risk assessment is the basis for risk prevention and control. For these reasons, virtual enterprises should attach great importance to risk assessment. Figure 7 shows the relationship between risk control accuracy and efficiency of the foundation risk, operation risk, and disbandment risk of virtual enterprise under optimal allocation and selective optimization.

As the third party of the virtual enterprise, the industry association can build a complete enterprise information database with government functional departments and conduct onsite inspections and evaluations of registered enterprises to verify the accuracy of the information. At the same time, relevant information will be publicized on the collaboration platform, and evaluations by alliance members will be accepted. The accuracy, fairness, and transparency of enterprise information reduce the asymmetry of information among cooperative enterprises, thereby reducing the obstacles to collaboration between enterprises and improving the efficiency of the formation of virtual enterprises. Under normal circumstances, the choice of partners depends on the corporate brand and historical integrity records. Before forming a stable alliance, the two parties need to conduct on-site inspections of the alliance partners to ensure that the other party has sufficient production and payment capabilities. By understanding the business scale, product quality, after-sales service, etc., the credibility of the other party can be assessed, and these obstacles affect the agility of the virtual enterprise and make the healthy operation of the virtual enterprise not guaranteed. On the collaborative platform, the dynamic credit evaluation system established by the industry associations dynamically assesses the task execution and 
payment capabilities of each alliance member enterprise and timely feeds back the credit changes of other enterprises to the alliance member enterprises, which can ensure the healthy operation of the virtual enterprise.

\section{Conclusions}

This paper constructed a risk control model for virtual enterprise based on distributed decision-making model, analyzed the multiobjective model and interval programming model of risk control, established a risk control approach for virtual enterprise based on distributed decisionmaking model, performed the optimal allocation of risk control funds and the selective optimization of backup allies, and finally conducted a case analysis. Before forming a stable alliance, the two parties need to conduct on-site inspections of the alliance partners to ensure that the other party has sufficient production and payment capabilities, and evaluate each other's performance by understanding the business scale, product quality, after-sales service, etc. Virtual enterprises cross the theory of enterprise boundaries, enabling a single enterprise to incorporate a large number of external resources belonging to other enterprises into the track of self-development. For the deviation caused by the individual characteristics of the partners, the plan between the partners is adjusted through the negotiation process to achieve the expected goals; the deviation caused by the changes in the structure and the external environment is an exception, and the cooperation mode and the goal of the collaborative plan have been realized. The distributed decision-making model comes from insufficient estimation of technical complexity in advance, and technical issues that are difficult to solve and market opportunities are the reasons for the existence of virtual enterprises. Moreover, a virtual enterprise can virtualize some functions and retain only the core functions, while other functions can break through the limitations of their own functions with the help of external forces. The study results show that, in view of the diversity of relationships between alliance businesses and the complexity of the distribution of cooperative areas, the distributed decisionmaking model can more reasonably describe the relationship between alliance members and accurately control the risks of virtual enterprise from multiple angles, which can effectively manage the risks of virtual enterprise. The study results of this paper provide a reference for further research on the risk control of virtual enterprise based on distributed decision-making model.

\section{Data Availability}

The data used to support the findings of this study are available from the author upon request.

\section{Conflicts of Interest}

The author declares no known conflicts of financial interest or personal relationships that could have appeared to influence the work reported in this paper.

\section{References}

[1] B. L. Sadigh, H. O. Unver, S. Nikghadam, E. Dogdu, A. M. Ozbayoglu, and S. E. Kilic, "An ontology-based multiagent virtual enterprise system (OMAVE): part 1: domain modelling and rule management," International Journal of Computer Integrated Manufacturing, vol. 30, no. 2-3, pp. 320-343, 2017.

[2] N. C. Narendra, A. Norta, M. Mahunnah, L. Ma, and F. M. Maggi, "Sound conflict management and resolution for virtual-enterprise collaborations," Service Oriented Computing and Applications, vol. 10, no. 3, pp. 233-251, 2016.

[3] H. O. Nyongesa, G. W. Musumba, and N. Chileshe, "Partner selection and performance evaluation framework for a construction-related virtual enterprise: a multi-agent systems approach," Architectural Engineering and Design Management, vol. 13, no. 5, pp. 344-364, 2017.

[4] S. Nikghadam, B. L. Sadigh, A. M. Ozbayoglu, H. O. Unver, and S. E. Kilic, "A survey of partner selection methodologies for virtual enterprises and development of a goal programming-based approach," The International Journal of Advanced Manufacturing Technology, vol. 85, no. 5-8, pp. 1713-1734, 2016.

[5] G. W. Musumba and P. K. Wamuyu, "Virtual enterprise as a multi agent system," International Journal of Agent Technologies and Systems, vol. 8, no. 1, pp. 46-68, 2016.

[6] A. C. Kalloniatis, T. A. McLennan-Smith, and D. O. Roberts, "Modelling distributed decision-making in command and control using stochastic network synchronisation," European Journal of Operational Research, vol. 284, no. 2, pp. 588-603, 2020.

[7] Y. Wang and C. Yu, "Social interaction-based consumer decision-making model in social commerce: the role of word of mouth and observational learning," International Journal of Information Management, vol. 37, no. 3, pp. 179-189, 2017.

[8] S. Lee and K.-K. Seo, "A hybrid multi-criteria decisionmaking model for a cloud service selection problem using BSC, fuzzy Delphi method and fuzzy AHP," Wireless Personal Communications, vol. 86, no. 1, pp. 57-75, 2016.

[9] P. Tornvall, O. Collste, E. Ehrenborg, and H. Järnbert-Petterson, "A case-control study of risk markers and mortality in takotsubo stress cardiomyopathy," Journal of the American College of Cardiology, vol. 67, no. 16, pp. 1931-1936, 2016.

[10] I. A. Saleh, O. I. Alsaif, and M. A. Yahya, "Optimal distributed decision in wireless sensor network using gray wolf optimization," IAES International Journal of Artificial Intelligence (IJ-AI), vol. 9, no. 4, pp. 646-654, 2020.

[11] S. J. Darak, C. Moy, and J. Palicot, "Distributed decision making policy for frequency band selection boosting RF energy harvesting rate in wireless sensor nodes," Wireless Networks, vol. 24, no. 8, pp. 3189-3203, 2018.

[12] C. H. Chung, C. Y. Lin, and E. Lin, "The management of end user computing in a distributed decision support systems environment," Journal of Computer Information Systems, vol. 30, no. 1, pp. 26-32, 2016.

[13] G. Avventuroso, M. Silvestri, and P. Pedrazzoli, "A networked production system to implement virtual enterprise and product lifecycle information loops," IFAC-PapersOnLine, vol. 50, no. 1, pp. 7964-7969, 2017.

[14] M. M. Butt, I. Dey, M. Dzaferagic, M. Murphy, N. Kaminski, and N. Marchetti, "Agent-based modeling for distributed decision support in an IoT network," IEEE Internet of Things Journal, vol. 7, no. 8, pp. 6919-6931, 2020. 
[15] B. L. Sadigh, S. Nikghadam, A. M. Ozbayoglu, H. O. Unver, E. Dogdu, and S. E. Kilic, "An ontology-based multi-agent virtual enterprise system (OMAVE): part 2: partner selection," International Journal of Computer Integrated Manufacturing, vol. 30, no. 10, pp. 1072-1092, 2017.

[16] T. A. Seidel, "Auditors' response to assessments of high control risk: further insights," Contemporary Accounting Research, vol. 34, no. 3, pp. 1340-1377, 2017.

[17] N. Patrignani and I. Kavathatzopoulos, "Cloud computing: the ultimate step towards the virtual enterprise?" ACM Sigcas Computers and Society, vol. 45, no. 3, pp. 68-72, 2016.

[18] C. R. Makanjee, A.-M. Bergh, and W. A. Hoffmann, "Distributed decision making in action: diagnostic imaging investigations within the bigger picture," Journal of Medical Radiation Sciences, vol. 65, no. 1, pp. 5-12, 2018.

[19] M. Oprea, "ABVE-frame: an agent-based virtual enterprise development framework," Ai Communications, vol. 30, no. 2, pp. 117-140, 2017.

[20] V. Pavlenko, T. Pavlenko, O. Morozova, A. Kuznetsova, and O. Voropai, "Solving transport logistics problems in a virtual enterprise through artificial intelligence methods," Transport Problems, vol. 12, no. 2, pp. 31-42, 2017.

[21] A. Javed and M. Yasir, "Virtual social enterprise: modeling sustainability of an enterprise by digital intervention," World Journal of Entrepreneurship, Management and Sustainable Development, vol. 15, no. 2, pp. 182-196, 2019.

[22] I. Polyantchikov, E. Shevtshenko, T. Karaulova, T. Kangilaski, and L. M. Camarinha-Matos, "Virtual enterprise formation in the context of a sustainable partner network," Industrial Management \& Data Systems, vol. 117, no. 7, pp. 1446-1468, 2017.

[23] I.-M. Jiang, C. C. Lo, A. Karathanasopoulos, and K. Skindilias, "A risk control tool for foreign financial activities-a new derivatives pricing model," Journal of Asset Management, vol. 18, no. 4, pp. 269-294, 2017.

[24] G. Sarens and G. D’Onza, “The perception of financial analysts on risk, risk management, and internal control disclosure: evidence from Belgium and Italy," International Journal of Disclosure and Governance, vol. 14, no. 2, pp. 118-138, 2017.

[25] I. Santosa and R. Raras Yusvinindya, "Risk analysis and control of personal data protection in the population administration information system," Jurnal RESTI (Rekayasa Sistem dan Teknologi Informasi), vol. 3, no. 3, pp. 496-504, 2019. 